\title{
Broiler ascites: a review of the ascites work done at the poultry section of the Onderstepoort Veterinary Institute 1981- 1990
}

\author{
F.W. HUCHZERMEYER \\ Department of Paraclinical Sciences, Faculty of Veterinary Science, University of \\ Pretoria, Onderstepoort, 0110 South Africa \\ Corresponding author: crocvet@mweb.co.za
}

Broiler ascites, first seen in the form of a high altitude disease, has increased in importance world-wide in direct proportion to the improvement in growth performance of modern broilers. At the same time, the incidence has spread gradually from high altitude (above $2000 \mathrm{~m}$ ) down to sea level, which gave rise to proposals of alternative causes including infections, toxins and metabolic disorders. Our work centred on anatomical and physiological aspects and included hypoxia models, chemotherapy and selection for genetic resistance. The latter led to the development of ascites-resistant lines, which allowed resistant stock to become commercially available in South Africa.

The closure of the Poultry Section of the Onderstepoort Veterinary Institute brought ongoing ascites research to an abrupt end and some of the completed work was never published. This review of completed, ongoing and planned ascites work was at the time compiled as final report to the Director of the Institute in 1990. It came to light again recently and has been edited for publication. It also includes a new hypothesis on the reasons for the susceptibility of the domestic fowl and particularly broilers to hypoxic ascites.

Keywords: broiler; ascites; hypoxia; cold; respiratory control

\section{The hypoxia cascade}

\section{HYPOXIA AND PULMONARY VASOCONSTRICTION (FIGURE 1)}

Altitude disease is caused by hypoxia. The sequence of events leading from hypoxia to ascites, at the time partially elucidated partially hypothesised, has been explained by Huchzermeyer (1989). Hypoxia causes contraction of the lung arteries. This can be visualised by lung angiography which entails injecting the lung arteries of sacrificed birds with a contrast medium after which radiographs are taken (Reid, 1986). The wide

(C) World's Poultry Science Association 2012

World's Poultry Science Journal, Vol. 68, March 2012

Received for publication February 15, 2011

Accepted for publication August 14, 2011 
pulmonary arteries of normal birds contrast with the contracted arteries of ascitic birds (own unpublished findings).

This pulmonary vasoconstriction is normally designed to shunt blood away from malfunctioning parts of the lung, but in generalised hypoxia it leads to a further exaggeration of the problem, resulting in a vicious cycle. It also increases the pulmonary arterial pressure, which can be measured in normal birds (Guthrie et al., 1987), however, it is not possible to these measurements in ascitic birds as they tended to die during the procedure.

Chronic pulmonary vasoconstriction causes a thickening (hypertrophy) of the muscular layer of the pulmonary arteries, which can be measured in histological preparations. A study comparing the pulmonary arteries of normal broilers raised at sea level and at high altitude $( \pm 1600 \mathrm{~m})$ with those of ascitic broilers was in progress but remained unfinished.

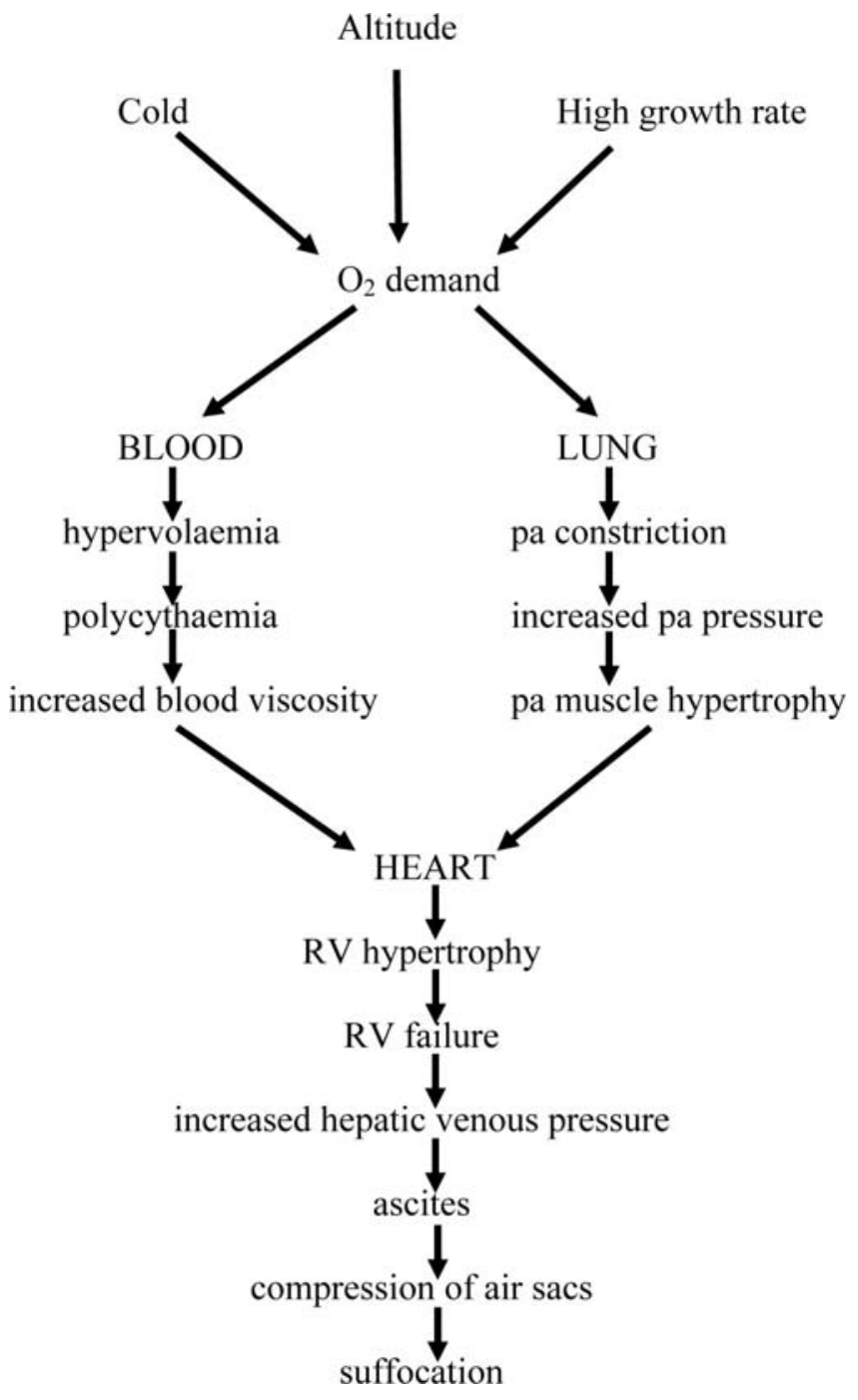

Figure 1 Hypoxia cascade (pa = pulmonary artery; $R V=$ right ventricle) 


\section{RIGHT VENTRICULAR HYPERTROPHY}

Pulmonary arterial vasoconstriction increases the work-load of the right ventricle of the heart resulting in an increase of right ventricular mass. This increase in relation to total heart (ventricular) mass is believed to be in direct proportion to the increase of pulmonary arterial pressure (Cueva et al., 1974). The RRV can be determined post mortem by dissecting and weighing the heart and this is a valuable tool in the evaluation of ascites trials (right ventricular mass divided by total ventricular mass $=$ RRV) (Huchzermeyer and De Ruyck, 1986; Julian, 1987). Normal values range from 0.15 to 0.25 while ascitic birds have RRV values of 0.30 to 0.60 . The increase in right ventricular mass is not only caused by a thickening of the wall of the right ventricle; contrary to the situation in mammals the hypertrophic right ventricle of broilers extends further towards the apex of the heart and over a larger proportion of the circumference of the left ventricle (unpublished). A concomitant thinning of the wall of the left ventricle was reported by Julian et al. (1987).

\section{HYPERVOLAEMIA AND POLYCYTHAEMIA}

As a result of pulmonary arterial vasoconstriction and further aggravated hypoxia, the body tries to compensate by producing more red blood cells (polycythaemia) (Maxwell et al., 1986) and increasing the blood volume (hypervolaemia). Polycythaemia is determined by calculating the percentage of packed red blood cells in a volume of centrifuged blood (haematocrit, HCT). While normal broilers have HCT values of $18 \%$ to $30 \%$, the values of ascitic birds ranged from $35 \%$ to $60 \%$ (unpublished).

High HCT values increase the viscosity of the blood and add to the overload of the right ventricle of the heart. Using a simple drop method a drastic increase of blood viscosity was found only with near terminal HCT values (unpublished). A much higher viscosity together with HCT values of up to $80 \%$ has been reported in hypoxic rats (Ou and Smith, 1984). Blood viscosity has been successfully reduced in ponies by the use of warfarin (Amin et al., 1984).

Hypervolaemia is believed to add to the workload of the right heart (Julian, 1987). Our results showed that blood volume increased in direct relation to the increase of RRV. Plasma volume increased during the early stage of the development of ascites but decreased again in the terminal stage with fluid loss into the peritoneal cavities ascites (unpublished).

In non-ascitic birds there is a poor relationship between HCT and RRV values because of very large individual variations (own unpublished findings). HCT therefore does not appear to be a useful indicator to identify ascites susceptible birds. At one stage it was thought that there was a correlation between group HCT and RRV values. However, testing the progeny of these groups two years later gave unmatched results (unpublished). Here it must be emphasised that HCT results obtained during summer and/or at submaximal growth rates will be unreliable. Our own work was carried out mostly at a moderate altitude of $\pm 1200 \mathrm{~m}$.

\section{ASCITES}

At an advanced stage of right ventricular hypertrophy, excessive blood is dammed back into the portal vein of the liver, probably because of malocclusion of the right atrioventricular valve (Julian et al., 1987). This leads to a severe distension of the portal vein, which could be demonstrated on whole-body crosscuts of frozen ascitic broilers with portal vein diameters in excess of $20 \mathrm{~mm}$ (unpublished).

The increased venous pressure within the liver causes the plasma to filter out of the hepatic sinuses into the different peritoneal sacs in the abdominal cavity (Bezuidenhout, 1988). This accumulation of partially clotted fluid in the peritoneal sacs constitutes 
ascites. Compression of the abdominal air sacs by the filled peritoneal sacs finally suffocates the bird.

Atrial natriuretic factor (ANF), a hormone that controls blood volume, is deficient in cardiomyopathic hamsters with congestive heart failure (Dlouha and McBroom, 1986). ANF is secreted when the atrial muscle fibres extend as a result of increased blood volume. It then causes an increased production of urine in an attempt to reduce blood volume (Cantin and Genest, 1986). Consequently ANF depletion may lead to the rapid terminal increase in blood volume in ascitic birds due to the cessation of stimulating diuresis.

\section{Ancillary investigations}

\section{CHEMOTHERAPY}

In collaboration with Dr J.H. du Preez, an attempt was made to suppress pulmonary vasoconstriction in 3265 broiler chicks at an altitude of $1450 \mathrm{~m}$ during winter (July/ August, 1986) by continuous administration of nitrofurantoin $(200 \mathrm{~g} / \mathrm{t})$ and a ketanserin analogue (Jansen Pharmaceuticals) (Archer et al., 1985; Van de Water et al., 1985) at 2g/t in pelleted feed. While the nitrofurantoin had no effect, the ketanserin analogue reduced the incidence of ascites from $15.1 \%$ in the control birds to $12.73 \%$ and the mean RRV from 0.28 to 0.245 without affecting mean live mass and feed conversion ratio at the end of the trial. Wideman et al. (1995a) achieved similar results with feeding furosemide to broilers at winter temperatures. The incidence of ascites in broilers has also been reduced by the supplementation of l-arginine (Wideman et al., 1995b) and vitamin C (Hassanzadeh and Ladmakhi et al., 1997).

\section{SELECTION FOR RESISTANCE}

Evaluation of RRV results of trial flocks led to the discovery that even in highly susceptible groups there were some normal birds and in resistant flocks there were some susceptible birds (Huchzermeyer et al., 1988). In the statistical evaluation of trial results this biphasic distribution of RRV values therefore appears to be at least as important as the actual means and standard deviations.

The discovery of resistant birds in generally susceptible flocks was the basis for the genetic selection in South Africa for ascites resistance. Broiler breeder chicks were reared at altitude $(>1600 \mathrm{~m})$ on full ration for maximum growth ('broilerised') and the survivors were selected for breeding (unpublished). This resistance did not appear to interfere with other performance traits, especially growth rate and carcass conformation.

\section{HYPOXIA MODELS}

Because of the seasonal incidence of ascites in the field, namely in winter, our work was progressing very slowly. This induced us to look for alternative models.

Hypoxia can be induced by simulating altitude in a chamber ventilated with a mixture of normal air and additional nitrogen (Burton et al., 1969; Besch and Kadono, 1978) or from which air is pumped against a controlled leak consisting of a partially opened gas tap. Such a hypobaric chamber was constructed from a 2001 oil drum and a small vacuum pump $(25 \mathrm{l} / \mathrm{min}$ ). The achieved simulated altitude was read from a climbing altimeter suspended behind the plexiglas panel which closed the chamber. Temperature control remained a problem particularly in summer when cold tap water was not available for cooling. Under these conditions growth rates of the birds in the chamber remained sub-maximal. Consequently only a few cases of ascites could be induced.

The predominant role of pulmonary arterial vasoconstriction in association with right 
ventricular hypertrophy in systemic hypoxia was underscored by our finding that a nonfebrile anaemia caused by an infection with Aegyptianella pullorum in broilers (Huchzermeyer et al., 1987) and with Plasmodium durae in turkeys (Huchzermeyer, 1988 ) also produced right ventricular hypertrophy and even ascites. The anaemia must be non-febrile, as an undisturbed appetite is necessary to maintain high levels of oxygen consumption. In contrast to human malaria, avian malarias are non-febrile, as no endotoxin is produced by the avian parasites. Endotoxin was not detected in the serum of fowls infected with $A$. pullorum (unpublished).

We were unable to produce increased RRV values in broiler chicks with coccidial infections (Eimeria tenella and E. necatrix), which cause a severe anaemia but are febrile (unpublished). However, Plasmodium gallinaceum infection could be another suitable hypoxia model in broilers.

Phenylhydrazine is used to induce anaemia in other species (Dornfest et al., 1983; Long, 1926. When we administered phenylhydrazine to broilers, the birds became anorexic and did not develop right ventricular hypertrophy (unpublished).

\section{Primary causes of hypoxia}

Further examination of the hypoxia cascade should concentrate on the primary causes of hypoxia. After having achieved a reasonable understanding of the chain of events, our interest was drawn to the following questions:

- Why should broilers die from hypoxia even at sea level?

- Is there an anatomical difference between susceptible and resistant birds?

- Why is ascites limited to broilers while turkeys and ducks achieve comparable growth rates?

\section{GROWTH RATE AND OXYGEN CONSUMPTION}

The increase in the incidence of ascites in broilers parallel to increasing growth rates has already been mentioned. A reduction of feed intake by feeding mash instead of pellets, at least during some of the rearing period, is a widely practiced method of controlling ascites-associated mortalities. Similar results can be achieved by feed restriction (Rubio and Lopez Coello, 1986; Suarez and Rubio, 1989). A reduced growth rate as consequence of a reduced feed intake is believed to cause a direct reduction in oxygen consumption.

\section{COLD}

The role of cold as a predisposing factor of ascites mortalities was investigated by measuring oxygen consumption of resting birds at different temperatures. Cold caused a sharp increase in oxygen consumption (Huchzermeyer et al., 1989). An increased incidence of ascites in broilers kept in a cold environment has also been reported by Julian et al. (1989). Inadequate ventilation of broiler houses during winter (Maxwell et al., 1989) and emission of carbon dioxide by brooders (Julian and Wilson, 1984) have been cited as alternative causes for the increase of broiler ascites during winter.

\section{RESPIRATORY DISEASE}

Respiratory disease can interfere with the oxygen transfer efficacy of the lung. As with anaemia, they would have to be non-febrile to cause severe hypoxia. One such condition is pulmonary aspergillosis (Bergmann et al., 1979; Da Silva, 1985). We saw a severe outbreak of ascites with right ventricular hypertrophy in broilers kept on a litter of very 
dusty hardwood sawdust on a prison farm that used sawdust from the prison workshop as litter (unpublished).

\section{OXYGEN TRANSFER CAPACITY}

All these findings point to the oxygen transfer capacity of the lung as the most likely factor in determining susceptibility or resistance to ascites. In other words, lungs of susceptible birds appear to have an inadequate oxygen transfer capacity. This does not mean that hypoxic birds should breathe more frequently or deeper as postulated by Julian et al. (1989). In all warm blooded species the respiratory response to chronic hypoxia is weakened. In fact the panting seen in birds kept at elevated temperatures may prevent the induction of hypoxia in spite of the increased oxygen demand seen at high temperature (Huchzermeyer et al., 1989). Consequently neither respiratory rate nor volume can be used as measurement of chronic pulmonary insufficiency, but rather the arterial blood gases $\mathrm{paO}_{2}$ and $\mathrm{paCO}_{2}$, as well as $\mathrm{VO}_{2}$ (Sneddon et al., 1989).

While fast growing turkeys showed a reduction of relative lung volume when compared with turkeys from slow growing strains (Timmwood et al., 1987) such a difference did not appear to be present in a preliminary comparison of susceptible and resistant broilers (Sneddon et al., 1989).

An ultrastructural morphometric comparison of lungs of the domestic fowl (White Leghorn) and its wild ancestor, the red jungle fowl, showed differences of the thickness of the blood-gas barrier as well as in relative exchange surface (Vidyadaran et al., 1987; 1988; 1990). If such differences exist between two different strains of the same species, there is no reason why they could not exist between individuals. These differences could therefore be the anatomical basis for the difference between susceptible and resistant broilers.

A computerised electron microscope for this kind of morphometric study was available at the University of Giessen in Germany, where similar studies had been carried out on lungs of various vertebrate species (Duncker, 1972; Duncker and Kriete, 1987; Duncker and Güntert, 1989). During a visit to the University of Giessen in 1989 our research group was allowed access to the facilities, however due to the closure of the Section this offer could not be taken up.

It appears that an anatomical pulmonary insufficiency, the exact nature of which still needs to be determined, does not allow affected high performance broilers to extract sufficient oxygen from the air in order to meet the high metabolic demand, particularly under adverse conditions, e.g. cold. Only when the exact nature of ascites susceptibility has been clarified, will it be possible to search for clinical parameters allowing the selection of live birds for ascites resistance.

The partial success achieved so far and the present availability of resistant stock had induced a certain degree of apathy towards further ascites research in South Africa, which with the closure of the Poultry Section came to a standstill. However, a review of the literature up to that point led to the formulation of a new hypothesis regarding the particular susceptibility of broilers in comparison to turkeys and ducks.

\section{A new hypothesis}

Several factors combine to cause hypoxic broiler ascites, in particular an achieved fast growth rate (Julian et al., 1987), altitude (Sillau et al., 1980; Hernandez, 1987), cold (Julian et al., 1989) and a genetic predisposition independent of potential growth rate (Huchzermeyer et al., 1988; Smith, 1989). However, two questions remain: Why these 
birds should not be able to compensate for hypoxia and why this disease should now occur at sea level (Albers and Frankenhuis, 1990).

We propose that the explanation lies in the evolutionary history of the domestic fowl, whose ancestor, the red jungle fowl, was adapted to a tropical environment where it was not obliged to perform sustained exercise, neither in flight nor running. The red jungle fowl has, however, a higher anatomical gas diffusion capacity $(25 \%)$ than the domestic fowl (Vidyadaran et al., 1990). Taking this into consideration, according to Duncker (1972) only the neopulmo ( $\pm 20 \%$ of total lung volume) is normally used for resting respiration, there may be a large discrepancy between resting respiratory capacity and body mass in the broiler. Duncker's hypothesis may have been contradicted though by the findings of Holle et al. (1978). Another modern bird with a fast growth rate, the domestic turkey, shows a discrepancy between lung and body mass (Timmwood et al., 1987) without being prone to hypoxic ascites, although a few cases of ascites at high altitude have been reported by Duff et al. (1995). Nor does the domestic duck suffer from this condition in spite of a growth performance similar to that of broilers, even though some cases of duck ascites with right ventricular hypertrophy have been reported by Julian (1988).

In addition to a possible ventilation mismatch, the domestic fowl shows a week ventilatory response to acute hypoxia (Brackenbury et al., 1982a; 1982b; 1985), while reacting much more strongly to hyperthermia and elevated $\mathrm{pCO}_{2}($ Brackenbury et al., 1982a; 1983; Estavillo, 1988).

For a tropical bird, such as the jungle fowl, hyperthermia may be expected to be a major determinant in respiratory control, as hyperthermia would be an early and important consequence of exercise. However, such a mechanism would seriously compromise respiratory control of a non-exercising broiler kept in a cold environment even at low altitude. The increased oxygen demand with cold (Huchzermeyer et al., 1989; Meltzer, 1987) could further contribute to a hypoxic state, despite the concomitant increase in $\mathrm{pCO}_{2}$, which would tend to stimulate ventilatory activity. Although winter conditions in broiler houses rarely produce extremely low temperatures, additional heating has been found to be effective in reducing the winter incidence of ascites (Hernandez, 1984).

The ancestor of the domestic turkey evolved in a temperate climate with potentially very cold winter temperatures. Of necessity it must have developed different mechanisms of ventilatory control, thereby enabling it to respond more effectively to hypoxia, particularly if accompanied by cold. This would also apply to the domestic duck, which, as a diving bird of arctic origin with an ancestor capable of sustained flight, can be presumed also to have more efficient respiratory control mechanisms.

In man, chronic exposure to altitude blunts the hypoxic response (Weil et al., 1971). Although not demonstrated, this same adaptation probably also might occur in the domestic fowl, if there are any $\mathrm{O}_{2}$ receptors that could be blunted. Furthermore, obesity is known to hinder ventilatory movements during sleep in man, which thus causes hypoxic pulmonary hypertension (Reeves, pers. comm.). A heavy broiler resting on its sternum could be subject to similar forces.

\section{Conclusions}

It is believed that all broilers are compromised by their innate inability to respond to hypoxia. The genetic predisposition of certain lines and families to ascites will be expressed as an aggravated resting pulmonary insufficiency, namely an imbalance between body mass and volume either of the neopulmo or both lung compartments 
and/or an increased blood/gas barrier. The realisation that the fowl's respiratory control is unable to respond to the increased oxygen demand caused by cold could have far reaching animal welfare implications.

\section{Acknowledgements}

My sincere thanks for their contribution to our knowledge are due to my colleagues and co-workers at the time: M.A. Cloryga, A.M.C. de Ruyck, R.S. Verster, J.A. Cilliers, C.D. Diaz-Lavigne, R.A. Bartkowiak, P.R. Guinane and A.J. Guthrie, and in particular A.J. Bezuidenhout and the late J.G. van der Walt, who participated in the formulation of the 'new' hypothesis.

\section{References}

ALBERS, G. and FRANKENHUIS, M. (1990) Ascites, a high altitude disease in the lowlands. Poultry-Misset 1990: $24-25$.

AMIN, T.M., ALLEN, B.V. and COLLES, C.M. (1984) Effects of warfarin on blood rheology in navicular diseases. Research in Veterinary Science 40: 308-313.

ARCHER, B.L., EATON, J.N., CHESLER, E. and WEIR, E.K. (1985) Nitrofurantoin reduces chronic hypoxic pulmonary hypertension in rats. Federation Proceedings 44: 1755.

BERGMANN, V., MÜLLER-MOLENAR, K. and BIRNBAUM, H. (1979) Zum Auftreten eines Hydropericard-Ascites-Syndroms (, Oedemkrankheit“) in Broilerbeständem. Monatshefte für Veterinärmedizin 34: 626-628.

BESCH, E.L. and KADONO, H. (1978) Cardio-pulmonary responses to acute hypoxia, in: PIJPER, J. (Ed.) Respiratory function in birds, adult and embryonic, pp. 71-78 (Berlin, Springer).

BEZUIDENHOUT, A.J. (1988) Ascites and the anatomy of the peritoneal sacs of broilers. Onderstepoort Journal of Veterinary Research 55: 23-25.

BRACKENBURY, J.H., GLEESON, M. and AVERY, P. (1982a) Control of ventilation in running birds: Effects of hypoxia, hyperoxia and $\mathrm{CO}_{2}$. Journal of Applied Physiology 53: 1397-1404.

BRACKENBURY, J.H., GLEESON, M. and AVERY, P. (1982b) Respiration in exercising fowl. III. Ventilation. Journal of Experimental Biology 96: 315-324.

BRACKENBURY, J.H., GLEESON, M. and AVERY, P. (1983) Effects of $\mathrm{pCO}_{2}$ on respiratory pattern during thermal and exercise hyperventilation in domestic fowl. Respiration Physiology 54: 109-119.

BRACKENBURY, J.H., GLEESON, M. and AVERY, P. (1985) Separate and combined effects of temperature and hypoxia on breathing pattern in the domestic fowl. Journal of Comparative Physiology $B$ 156: 109-133.

BURTON, R.R., SMITH, A.H., CARLISLE, J.C. and SLUKA, S.J. (1969) Role of haematocrit, heart mass, and high altitude exposure in acute hypoxia tolerance. Journal of Applied Physiology 27: 49-52.

CANTIN, M. and GENEST, J. (1986) The heart as an endocrine gland. Scientific American 254 (2): 62-67.

CUEVA, S., SILlAU, H., VALENZUELA, A. and PLOOG, H. (1974) High altitude induced pulmonary hypertension and right heart failure in broiler chickens. Research in Veterinary Science 16: 370-374.

DA SILVA, J.M.L. (1985) South America. Lack of diagnostic laboratories. Poultry International August 1985 : 14-18.

DLOUHA, H. and MCBROOM, M.J. (1986) Atrial natriuretic factor in taurine-treated normal and cardiomyopathic hamsters. Proceedings of the Society for Experimental Biology and Medicine 181: 411-415.

DORNFEST, B.S., NAUGHTON, B.A., JOHNSON, R. and GORDON, A.S. (1983) Hepatic production of erythropoietin in a phenylhydrazine-induced hemolytic state in the rat. Journal of Laboratory and Clinical Medicine 102: 274-285.

DUFF, J.P., VELA, M.W. and PAREDES, D. (1995) Ascites syndrome in a turkey reared above 2000 metres. Veterinary Record 137: 300.

DUNCKER, H.-R. (1972) Structure of the avian lung. Respiration Physiology 14:44-63.

DUNCKER, H.-R. and KRIETE, A. (1987) Morphometrie mit Hilfe der Bildanalyse. Spiegel der Forschung 4 (4): $5-9$.

DUNCKER, H.-R. and GÜNTERT, M. (1989) The quantitative design of the avian respiratory system from hummingbird to mute swan. Biona Report 3: 361-378. 
ESTAVILLO, J.A. (1988) Changes in ventilation by increased venous $\mathrm{CO}_{2}$ with constant arterial blood gases in the domestic fowl. Journal of Physiology 396: 97p.

GUTHRIE, A.J., CILlIERS, J.A., HUCHZERMEYER, F.W. and KILLEEN, V.M. (1987) Broiler pulmonary hypertension syndrome. II. The direct measurement of right ventricular and pulmonary artery pressures in the closed chest domestic fowl. Onderstepoort Journal of Veterinary Research 54: 599-602.

HASSANZADEH LADMAKI, M., BUYS, N., DEWIL, E., RAHIMI, G. and DECUYPERE, E. (1997) The prophylactic effect of vitamin $\mathrm{C}$ supplementation on broiler ascites incidence and plasma thyroid hormone concentration. Avian Pathology 26: 33-44.

HERNANDEZ, A. (1984) Disminución en la incidencia de la ascitis aviar de origen hipóxico con el incremento de la temperatura en los galpones. Proceedings of the 14th National Veterinary Congress, Cartagena, p. 6.

HERNANDEZ, A. (1987) Hypoxic ascites in broilers: A review of several studies done in Colombia. Avian Diseases 31: 658-661.

HOLLE, J.P., HEISLER, N. and SCHEID, P. (1978) Blood flow distribution in the duck lung and its control by respiratory gases. American Journal of Physiology 234: 146-154.

HUCHZERMEYER, F.W. (1988) Avian pulmonary hypertension syndrome. IV. Increased right ventricular mass in turkeys experimentally infected with Plasmodium durae. Onderstepoort Journal of Veterinary Research 55: 107-108.

HUCHZERMEYER, F.W. (1989) Broiler ascites research: Where are we? SAPA Poultry Bulletin 1989: 358.

HUCHZERMEYER, F.W., CILLIERS, J.A., DIAZ-LAVIGNE, C.D. and BARTKOWIAK, R.A. (1987) Broiler pulmonary hypertension syndrome. I. Increased right ventricular mass in broilers experimentally infected with Aegyptianella pullorum. Onderstepoort Journal of Veterinary Research 54: 113-114.

HUCHZERMEYER, F.W. and DE RUYCK, A.M.C. (1986) Pulmonary hypertension syndrome associated with ascites in broilers. Veterinary Record 119: 93.

HUCHZERMEYER, F.W., DE RUYCK, A.M.C. and VAN ARK, H. (1988) Broiler pulmonary hypertension syndrome. III. Commercial broiler strains differ in their susceptibility. Onderstepoort Journals of Veterinary Research 55: 5-9.

HUCHZERMEYER, F.W., VAN DER COLF, W.J. and GUINANE, P.R. (1989) Broiler ascites: Increased oxygen demand with cold may explain high winter incidence. SAPA Poultry Bulletin 1989: 474 \& 483.

JULIAN, R.J. (1987) The effect of increased sodium in the drinking water on right ventricular hypertrophy, right ventricular failure and ascites in broiler chickens. Avian Pathology 16: 61-71.

JULIAN, R.J. (1988) Ascites in meat-type ducklings. Avian Pathology 17: 11-21

JULIAN, R.J., FRIARS, G.W., FRENCH, H. and QUINTON, M. (1987) The relationship of right ventricular hypertrophy, right ventricular failure, and ascites to weight gain in broiler and roaster chickens. Avian Diseases 31: 130-135.

JULIAN, R.J., MCMILLAN, I. and QUINTON, M. (1989) The effect of cold and dietary energy on right ventricular hypertrophy, right ventricular failure and ascites in meat-type chickens. Avian Pathology 18: 675684.

JULIAN, R.J. and WILSON, J.B. (1984) Ascites in broiler chickens caused by high levels of carbon dioxide. Proceedings $56^{\text {th }}$ Northeastern Conference on Avian diseases. University Park, Pa, USA.

LONG, P.H. (1926) Experimental anemia produced by phenylhydrazine derivatives. Journal of Clinical Investigation 2: 329-342.

MAXWELL, M.H., DICK, L.A. and MITCHELL, M.A. (1989) Ectopic cartilaginous and osseous lung nodules induced in the young broiler by inadequate ventilation. Avian Pathology 18: 113-124.

MAXWELL, M.H., ROBERTSON, G.W. and SPENCE, S. (1986) Studies on an ascitic syndrome in young broilers. I. Haematology and pathology. Avian Pathology 15: 511-524.

MELTZER, A. (1987) Acclimatization to ambient temperature and its nutritional consequences. World's Poultry Science Journal 43: 33-44.

OU, L.C. and SMITH, R.P. (1984) Strain and sex differences in the cardiopulmonary adaptation of rats to high altitude. Proceedings of the Society for Experimental Biology and Medicine 177: 308-311.

REID, L.M. (1986) Structure and function in pulmonary hypertension. Chest 89: 279-288.

RUBIO, E. and LOPEZ COELLO, C. (1986) Efecto de una restricción alimenticia sobre la incidencia del síndrome ascítico. Proceedings 35th Western Poultry Disease Conference, pp 165-167, Mexico, Puerte Vallarta.

SILlAU, A.H., CUEVA, S. and MORALES, P. (1980) Pulmonary arterial hypertension in male and female chickens at 3300 m. Pflügers Archiv 336: 269-275.

SMITH, W. (1989) Progress of the broiler breeding programme at National Poultry Breeders. SAPA Poultry Bulletin 1989: 86-87.

SNEDDON, J.C., VAN DER WALT, J.B., SOLEY, J., HUCHZERMEYER, F.W., VERSTER, R.S. and GUINANE, P.R. (1989) Pulmonary hypertension syndrome in broilers. A pilot trial on physiological indices. Proceedings of the Conference of the South African Physiological Society, 85: 330-331, Dikhololo, South Africa. 
SUAREZ, E. and RUBIO, M. (1989) Uso de restricción como control parcial del síndrome ascítico. Veterinaria Mexicana 20: 193-195.

TIMMWOOD, K.I., HYDE, D.M. and PLOPPER, C.G. (1987) Lung growth of the turkey, Meleagris gallopavo. II. Comparison of two genetic lines. The American Journal of Anatomy 178: 158-169.

VAN DE WATER, A., WOUTERS, L., XHONNEUX, R. and RENEMAN, S. (1985) Cardiovascular effects of ketanserin in close-chest anesthetized dogs. Archives Internationales de Pharmacodynamie et de Thérapie 275: $267-278$

VIDYADARAN, M.K., KING, A.S. and KASSIM, H. (1987) Deficient anatomical capacity for oxygen uptake of the developing lung of the female domestic fowl when compared with the red jungle fowl. Schweizer Archiv für Tierheilkunde 129: 225-237.

VIDYADARAN, M.K., KING, A.S. and KASSIM, H. (1988) Quantitative studies of the lung of the domestic fowl. Pertanika 11: 229-238.

VIDYADARAN, M.K., KING, A.S. and KASSIM, H. (1990) Quantitative comparisons of lung structure of adult domestic fowl and red jungle fowl. Avian Pathology 19: 51-58.

WEIL, J.V., BYRNE-QUINN, E., SODAL, I.E., FILLEY, G.F. and GROVER, R.F. (1971) Acquired attenuation of chemoreceptor function in chronically hypoxic man at high altitude. The Journal of Clinical Investigation 50: 186-195.

WIDEMAN, R.F., ISMAEL, M., KOCHERA KIRBY, Y., BOTTJE, W.G., MOORE, R.W. and VARDEMAN, R.C. (1995a) Furosemide reduces the incidence of pulmonary hypertension syndrome in broilers exposed to cool environmental temperatures. Poultry Science 74: 314-322.

WIDEMAN, R.F., KOCHERA KIRBY, Y., ISMAEL, M., BOTTJE, W.G., MOORE, R.W. and VARDEMAN, R.C. (1995b) Supplemental 1-arginine attenuates pulmonary hypertension syndrome (ascites) in broilers. Poultry Science 74: 323-330. 